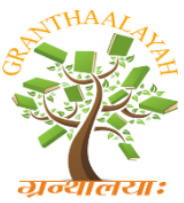

\author{
INTERNATIONAL JOURNAL OF RESEARCH - \\ GRANTHAALAYAH \\ A knowledge Repository
}

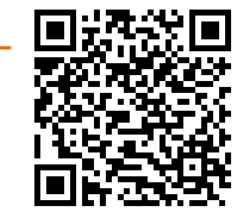

Science

\title{
REDUCTION OF ACTIVE POWER LOSS BY GROUP COMPETITION ALGORITHM
}

\author{
Dr.K.Lenin *1 \\ ${ }^{* 1}$ Professor, Department of EEE, Prasad V.Potluri Siddhartha Institute of Technology, Kanuru, \\ Vijayawada, Andhra Pradesh -520007, India
}

\begin{abstract}
This paper proposes Group Competition (GC) algorithm for solving optimal reactive power problem. Group Competition (GC) algorithm stimulated from the contest of sport teams in a sport group. A number of individuals as sport teams contend in a simulated group for numerous weeks. Based on the group schedule in every week, teams play in pairs and their game result is determined in terms of win or loss, given known the playing strength along with the teams' planned formations. Modeling an artificial match analysis, each team devises a new playing strategy for the subsequent week competition and this procedure is repetitive for number of seasons. In order to evaluate the validity of the proposed Group Competition (GC) algorithm, it has been tested on Standard IEEE 57,118 bus systems and simulation results reveal about the good performance of the proposed algorithm in reducing real power loss and voltage profiles are within the limits.
\end{abstract}

Keywords: Optimal Reactive Power; Transmission Loss; Group Competition; Optimization.

Cite This Article: Dr.K.Lenin. (2017). "REDUCTION OF ACTIVE POWER LOSS BY GROUP COMPETITION ALGORITHM.” International Journal of Research - Granthaalayah, 5(11), 260-270. https://doi.org/10.29121/granthaalayah.v5.i11.2017.2352.

\section{Introduction}

Optimal reactive power problem is key problem in secure \& economic operations of power system. The sources of the reactive power are the generators, synchronous condensers, capacitors, static compensators and tap changing transformers. The problem that has to be solved in a reactive power optimization is to determine the required reactive generation at various locations so as to optimize the objective function. Here the reactive power dispatch problem involves best utilization of the existing generator bus voltage magnitudes, transformer tap setting and the output of reactive power sources so as to minimize the loss and to enhance the voltage stability of the system. It involves a nonlinear optimization problem. Various mathematical techniques have been adopted to solve this optimal reactive power dispatch problem. These include the gradient method [1-2], Newton method [3] and linear programming [4-7].The gradient and Newton methods suffer from the difficulty in handling in equality constraints. To 
apply linear programming, the input- output function is to be expressed as a set of linear functions which may lead to loss of accuracy. Recently Global Optimization techniques such as genetic algorithms have been proposed to solve the reactive power flow problem [8,9]. This paper proposes Group Competition (GC) algorithm for solving reactive power problem. Group Competition (GC) algorithm stimulated from the contest of sport teams in a sport group. A number of individuals (solutions) as sport teams [10] contend in a simulated group for numerous weeks (iterations). Based on the group schedule in every week, teams play in pairs and their game result is determined in terms of win or loss, given known the playing strength (fitness value) along with the teams' planned formations. Modeling an artificial match analysis, each team devises a new playing strategy (a novel solution) for the subsequent week competition and this procedure is repetitive for number of seasons (stopping condition). In order to evaluate the validity of the proposed Group Competition (GC) algorithm, it has been tested on Standard IEEE 57,118 bus systems and simulation results reveal about the good performance of the proposed algorithm in reducing real power loss and voltage profiles are within the limits.

\section{Problem Formulation}

\subsection{Active Power Loss}

The objective of the reactive power dispatch is to minimize the active power loss in the transmission network, which can be described as follows:

$F=P L=\sum_{k \in N b r} g_{k}\left(V_{i}^{2}+V_{j}^{2}-2 V_{i} V_{j} \cos \theta_{i j}\right)$

Where F- objective function, $\mathrm{P}_{\mathrm{L}}$ - power loss, $\mathrm{g}_{\mathrm{k}}$-conductance of branch, $\mathrm{V}_{\mathrm{i}}$ and $\mathrm{V}_{\mathrm{j}}$ are voltages at buses $\mathrm{i}, \mathrm{j}, \mathrm{Nbr}$ - total number of transmission lines in power systems.

\subsection{Voltage Profile Improvement}

For minimizing the voltage deviation in PQ buses, the objective function becomes:

$F=P L+\omega_{v} \times V D$

Where VD - voltage deviation, $\omega_{\mathrm{v}}$ - is a weighting factor of voltage deviation.

Voltage deviation given by:

$V D=\sum_{i=1}^{N p q}\left|V_{i}-1\right|$

Where Npq- number of load buses

\subsection{Equality Constraint}

The equality constraint of the problem is represented by the power balance equation, where the total power generation must cover the total power demand and the power losses: 
$P_{G}=P_{D}+P_{L}$

Where $\mathrm{P}_{\mathrm{G}}$ - total power generation, $\mathrm{P}_{\mathrm{D}}$ - total power demand.

\subsection{Inequality Constraints}

The inequality constraints in the power system as well as the limits created to ensure system security. Upper and lower bounds on the active power of slack bus (Pg), and reactive power of generators $\left(\mathrm{Q}_{\mathrm{g}}\right)$ are written in mathematically as follows:

$P_{\text {gslack }}^{\min } \leq P_{\text {gslack }} \leq P_{\text {gslack }}^{\max }$

$Q_{g i}^{\min } \leq Q_{g i} \leq Q_{g i}^{\max }, i \in N_{g}$

Upper and lower bounds on the bus voltage magnitudes $\left(\mathrm{V}_{\mathrm{i}}\right)$ :

$V_{i}^{\min } \leq V_{i} \leq V_{i}^{\max }, i \in N$

Upper and lower bounds on the transformers tap ratios $\left(\mathrm{T}_{\mathrm{i}}\right)$ :

$T_{i}^{\min } \leq T_{i} \leq T_{i}^{\max }, i \in N_{T}$

Upper and lower bounds on the compensators reactive powers $\left(\mathrm{Q}_{\mathrm{c}}\right)$ :

$Q_{c}^{\min } \leq Q_{c} \leq Q_{C}^{\max }, i \in N_{C}$

Where $\mathrm{N}$ is the total number of buses, $\mathrm{N}_{\mathrm{T}}$ is the total number of Transformers; $\mathrm{N}_{\mathrm{c}}$ is the total number of shunt reactive compensators.

\section{Group Competition (GC) Algorithm}

Let us first have a look on the terminology related to team games, especially those terms which will be used metaphorically in Group Competition (GC) algorithm. A sports group is an organization that exists to provide a regulated competition for a number of people to compete in a specific sport. Group contest is generally used to refer to competitions involving team sports, not individual sports. A group competition may be contested in a number of ways. Each team may play every other team a certain number of times. In such a set-up, the team with the best record becomes champion, based on either a strict win-loss-tie system or on a points system where a certain number of points are awarded for a win, loss, or tie, while bonus points might also be added for teams meeting various criteria [11]. Generally each team has a playing style which is realized during the game via team formation. Formations are a method of positioning players on the pitch to allow a team to play according to their pre-set tactics. For example, the most common formations in soccer are variations of 4-4-2, 4-3-3, 3-2-3-2, 5-3-2 and 4-5-1 [12]. Usually each team has a best formation which is often related to the type of players available to the coach. It is vital for a sport team to devise suitable game plans and formations for every match. After each match, coaches analyze their own game and their next opponent game to plan 
on how they can develop a style of play to improve on their weaknesses or afford more on their strengths. The analysis also includes the evaluation of opportunities and threats that comes along with the unique dynamics of the team. This kind of match analysis is typically known as strengths/weaknesses/opportunities/threats (SWOT) analysis, which explicitly links internal (strengths and weaknesses) and external factors (opportunities and threats). The SWOT analysis provides a structured approach to conduct the gap analysis. A gap is sometimes spoken of as "the space between where we are and where we want to be". When the process of identifying gaps includes a deep analysis of the factors that have created the current state of the team, the groundwork has been laid for improvement planning. The gap analysis process can be used to ensure that the improvement process does not jump from identification of problem areas to proposed solutions without understanding the conditions that created the current state of the team. We can match the above terms to the standard evolutionary terms as follows: "group" stands for the population of solutions; "team i" stands for the ith solution in the population; "week" stands for "iteration"; "playing strength" stands for the "objective/fitness function value" and "a new formation" stands for "a new solution". In the reminder of the paper we use both terminologies, alternately. As a pseudo-evolutionary algorithm, the selection in Group Competition (GC) algorithm is the greedy selection which consists of always replacing the legacy formation, recognized as the best formation, with a more productive team formation having better playing strength. The algorithm terminates after a certain number of "seasons" (S) .

Before giving details of Group Competition (GC) algorithm, we first put forward several idealized rules which define the characteristics of artificial championship modelled by GC.

a) It is more likely that a team with better playing strength wins the game. The term "playing strength" refers to a team's ability to beat another team.

b) The outcome of the game is not predictable given known playing strength of the teams perfectly.

c) The probability that team $\mathrm{i}$ beats team $\mathrm{j}$ is assumed equal from both teams point of view.

d) The outcome of the game is only win or loss; there is no tie.

e) When team $\mathrm{i}$ beats team $\mathrm{j}$, any strength helped team i to win has a dual weakness caused team $\mathrm{j}$ to loss.

f) Teams focus only on their upcoming contest without regards of the other future matches. Formation settings are done just based on the previous week events.

Like many other evolutionary algorithms, Group Competition (GC) algorithm works with a population of solutions. Each member of the population is a potential solution that is related to one of teams and is interpreted as the team current formation. Given a function $\mathrm{f}$ of $\mathrm{n}$ variables, each solution such as $i$ can be represented with a vector of $n$ real numbers. We can see each variable as one of players where changing in the value of the variables may reflect changing in the job of the relevant player. We use $X_{i}^{t}=\left(x_{i 1}^{t} x_{i 2}^{t}, \ldots, x_{i n}^{t}\right)$ to address the formation of team $i$ at week t. By $f\left(x_{i}^{t}\right)$ we address the function value relevant to $x_{i}^{t}$. This value is called the playing strength along with formation $x_{i}^{t}$. by $B_{i}^{t}=\left(b_{i 1}^{t}, b_{i 2}^{t}, \ldots, b_{i n}^{t}\right)$ we address the best formation for team $\mathrm{i}$, experienced till week $\mathrm{t}$. This is the best solution that has been obtained so far for the ith member. To determine $B_{i}^{t}$, a greedy selection is conducted at each iteration between $X_{i}^{t}$ and $b_{i}^{t-1}$ based on the objective values criterion. 


\subsection{Generating The Group Contest Schedule}

Since Group Competition (GC) algorithm mimics the championship in a sport's group contest, it becomes required to schedule matches in the artificial group. A single round-robin schedule is utilized where each team plays every other participant once in each season. For a group contest of size L, single round robin tournament requires $L(L-1) / 2$ matches, because in each of $(L-1)$ rounds (weeks), $L / 2$ matches will be run in parallel (if $L$ is odd, there will be L rounds with $(L-1)$ / 2 matches, and one team have no game in that round). It is worth mentioning that the roundrobin tournament can be modelled as an edge-colouring problem in a diagraph [13].

\subsection{Champion/Loser Identification}

In a regular group contest system, teams compete on weekends and the outcome in terms of win, loss or tie is determined for each team. The degree of fit is proportional to the team's playing strength and is measured based on the distance with an ideal reference point. Let us consider teams $i$ and $j$ at week $t$, with formation strategies $x_{t}^{i}$ and $x_{t}^{j}$ and playing strengths $f\left(x_{i}^{t}\right)$ andf $f\left(x_{j}^{t}\right)$ respectively. Let $p_{i}^{t}$ be the chance of team $i$ to beat team $j$ at week $t$ ( $p_{j}^{t}$ can be defined accordingly). Let $\dot{f}$ be an ideal value (e.g., the optimal value or a lower bound on the optimal value). Based on the idealized rule 1 we can write,

$\frac{\mathrm{f}\left(\mathrm{x}_{\mathrm{i}}^{\mathrm{t}}\right)-\dot{\mathrm{f}}}{\mathrm{f}\left(\mathrm{x}_{\mathrm{j}}^{\mathrm{t}}\right)-\dot{\mathrm{f}}}=\frac{p_{j}^{t}}{p_{i}^{t}}$

In (10) we evaluate the teams based on their distance with a common reference point (the playing strength along with an ideal team formation), and thus the ratio of distances can determine the winning portion for each team.Based on the idealized rule 3 we can also write

$p_{i}^{t}+p_{j}^{t}=1$

From (10) and (11) we get

$p_{i}^{t}=\frac{\mathrm{f}\left(\mathrm{x}_{\mathrm{j}}^{\mathrm{t}}\right)-\dot{\mathrm{f}}}{\mathrm{f}\left(\mathrm{x}_{\mathrm{j}}^{\mathrm{t}}\right)+\mathrm{f}\left(\mathrm{x}_{\mathrm{i}}^{\mathrm{t}}\right)-2 \dot{\mathrm{f}}}$

To simulate the win or loss, a random number in $[0,1]$ is generated and if it is less than or equal to $p_{i}^{t}$, team $i$ wins and team $j$ losses; otherwise team $j$ wins and team $i$ losses. This procedure is consistent with idealized rule " $b$ " and "d".

\subsection{Setting Up A New-Fangled Team Construction}

In Group Competition (GC) algorithm, the artificial analysis of the team's previous performance (at week t) is treated as internal evaluation (strengths/weaknesses) and analysis of the opponent's previous performance is accounted as external evaluation (opportunities/threats) as shown in fig 1. In an artificial post match analysis of team $i$, if it has won (lost) the game from (to) team $j$ at week $t$, then it is assumed that the prosper (loss) is the direct consequence of the team strengths (weaknesses) or based on the idealized rule 5 , it is the direct consequence of the weaknesses 
(strengths) of team $\mathrm{j}$. Now, based on the group contest schedule at week $\mathrm{t}+1$, assume that the next mach of team $\mathrm{i}$ is with team 1 . If team 1 has won (lost) the game from (to) team $\mathrm{k}$ at week t, then this success (loss) and the team formation behind it might be a direct threat (opportunity) for team i. Apparently, this success (loss) is the result of some strengths (weaknesses). Focusing on the strengths (weaknesses) of team 1 , gives us an intuitive way of avoiding the possible threats (affording the opportunities). Instead, based on idealized rule 5, we can focus on weaknesses (strengths) of team k. For example, if team i was winner and team 1 was loser, then it is reasonable that team $\mathrm{i}$ focuses on the strengths which enabled it to win. At the same time it should focus on the weaknesses that caused team 1 to lose. These weaknesses may open opportunities for team $i$.

Let us first introduce the following indices:

$l=$ Index of the team that will play with team i based on the group contest schedule at week $t+1$.

$j=$ Index of the team that has played with team i based on the group contest schedule at week $t$.

$k=$ Index of the team that has played with team 1 based on the group contest schedule at week $t$.

\begin{tabular}{|l|l|l|l|l|}
\hline & $\begin{array}{l}\text { i:winner } \\
\text { 1:winner } \\
\text { Focussing on .. }\end{array}$ & $\begin{array}{l}\text { i:winner } \\
\text { l:loser } \\
\text { Focussing on .. }\end{array}$ & $\begin{array}{l}\text { i:winner } \\
\text { l:loser } \\
\text { Focussing on .. }\end{array}$ & $\begin{array}{l}\text { i:winner } \\
\text { l:loser } \\
\text { Focussing on .. }\end{array}$ \\
\hline $\mathrm{S}$ & $\begin{array}{l}\text { own strengths } \\
\text { (or weaknesses of j) }\end{array}$ & $\begin{array}{l}\text { own strengths } \\
\text { (or weaknesses of j) }\end{array}$ & - & - \\
\hline $\mathrm{W}$ & - & - & $\begin{array}{l}\text { own } \\
\text { weaknesses (or } \\
\text { strengths of j) }\end{array}$ & $\begin{array}{l}\text { own } \\
\text { weaknesses (or } \\
\text { strengths of j) }\end{array}$ \\
\hline $\mathrm{O}$ & - & $\begin{array}{l}\text { weaknesses of } \\
\text { l(or strengths } \\
\text { of k) }\end{array}$ & - & $\begin{array}{l}\text { weaknesses of } \\
\text { 1 (or strengths } \\
\text { of k) }\end{array}$ \\
\hline $\mathrm{T}$ & $\begin{array}{l}\text { strengths of 1 } \\
\text { (or weaknesses of k) }\end{array}$ & - & $\begin{array}{l}\text { strengths of l } \\
\text { (or weaknesses of k) }\end{array}$ & - \\
\hline
\end{tabular}

Figure 1: Actions suitable for team i when devising its formation for the next match (based on the win/loss states).

Given that normally teams play based on their current best formation (found it suitable over the times) while devising the required changes recommended by match analysis, therefore we can setup the new formation

$x_{i}^{t+1}=\left(x_{i 1}^{t+1}, x_{i 2}^{t+1}, \ldots, x_{i n}^{t+1}\right)$ for team $i(i=1, \ldots, L)$ at week $t+1$. It is rather unusual that coaches do changes in all or many dimensions of the team. Generally the number of changes is relatively low. To simulate the rate of changes $\left(q_{i}^{t}\right)$, we use a truncated geometric distribution [14]. Using a truncated geometric distribution, we can set the rate of changes dynamically, while putting more weights on the smaller rate of changes. The following formula gives the the smaller rate of changes. The following formula gives the random number of changes made in $B_{i}^{t}$ to get the new formation $x_{i}^{t+1}$. 
$q_{i}^{t}=\left[\frac{\ln \left(l-\left(l-\left(l-p_{c}\right)^{n}\right) r\right)}{\ln \left(l-p_{c}\right)}\right]: q_{i}^{t} \in\{1,2,3, \ldots, n\}$

Where $r$ is a random number in $[0,1]$ and $p_{c} \in(0,1)$ is an input parameter. Typically $p c$ is known as the probability of success in the truncated geometric distribution. The larger the value of pc , the smaller the number of changes are recommended.

\section{Group Competition (GC) Algorithm For Solving Reactive Power Problem}

To adapt Group Competition (GC) algorithm for solving reactive power, the key design is to preserve the main GC structure while adding a mechanism to handle constraints. We use the notion of Deb's constraint handling method [15] in the body of our algorithm. Deb's method uses a tournament selection operator, where two solutions are compared at a time, and the following selection criteria are always enforced:

a) Between 2 feasible solutions, the one with better fitness value wins.

b) If one solution is feasible and the other one is infeasible, the feasible solution wins.

c) If both solutions are infeasible, the one with the lowest sum of constraint violations is preferred.

In Deb's approach, feasible solutions are always considered better than infeasible ones. Therefore, this approach may have difficulties with problems in which the global optimum lies on the boundary between the feasible and the infeasible regions [16]. To remedy this deficiency, similar to the approach used in [17], we try to preserve diversity by allowing solutions having good value of objective functions remain in the population.

- If $x_{i}^{t}$ is feasible and $x_{j}^{t}$ is infeasible then team $i$ wins the game from $j$, that is $p_{i}^{t}=1$.

- Else if $x_{i}^{t}$ is infeasible and $x_{j}^{t}$ is feasible then team $j$ wins the game from $i$, that $i s p_{i}^{t}=0$.

- Else if $x_{i}^{t}$ is feasible and $x_{j}^{t}$ is feasible too, then the probability that team $i$ wins the game from $\mathrm{j}$ is calculated based on the objective function criterion as follows:

$p_{i}^{t}=\frac{f\left(x_{j}^{t}\right)-\dot{\mathrm{f}}}{f\left(x_{j}^{t}\right)+f\left(x_{i}^{t}\right)-2 \dot{\mathrm{f}}}$

- Else if is infeasible $x_{i}^{t}$ and $x_{j}^{t}$ is infeasible too, then the probability that team $i$ wins the game from $\mathrm{j}$ is calculated based on the total constraint violations criterion as follows:

$p_{i}^{t}=\frac{c v\left(x_{j}^{t}\right)-\hat{\mathrm{C}} v}{\hat{\mathrm{C}} v\left(x_{j}^{t}\right)+\hat{\mathrm{C}} v\left(x_{i}^{t}\right)-2 \hat{\mathrm{C}} v}$

In (15), $\hat{\mathrm{C}} v$ is the lowest value among the total constraint violations values observed so far (similar to the definition of $\dot{f}$ ). As soon as the search approaches feasible regions we will have $\hat{\mathrm{C}} v=0$. In order to increase the probability to generate better solutions, each team is allowed to generate a number of alternative formations in each week (multiple offspring are generated). The 
number of generated formations $\left(n_{f}\right)$ is a user defined parameter. Among the $n_{f}$ alternative formations generated for each team, we select one of them based on the sequential using of Deb's criteria with a modification on the third criterion as follows:

- If both solutions are infeasible then,

- If $\mathrm{r} \leq \mathrm{T}^{\mathrm{t}}$. The selection is based on conducting the greedy selection between them based on the objective value criterion.

Else

- The selection is based on conducting the greedy selection between them based on the total constraint violations criterion.

End if

We do not generate a predefined number of alternative formations (offspring) for each team. Instead we decrease the number of alternative formations systematically at certain milestones. Starting with $n_{f}=5$. We decrease $n_{f}$ by one every time that $\bmod (C E, N E / 5)=0$, where $C E$ is the solution counter ( $C E$ is increased by one whenever a new solution is generated). Therefore, the algorithm performs its final searches with $n_{f}=1$.

\section{Simulation Results}

At first Group Competition (GC) algorithm has been tested in standard IEEE-57 bus power system. The reactive power compensation buses are 18, 25 and 53. Bus 2, 3, 6, 8, 9 and 12 are PV buses and bus 1 is selected as slack-bus. The system variable limits are given in Table 1.

The preliminary conditions for the IEEE-57 bus power system are given as follows:

$\mathrm{P}_{\text {load }}=12.119$ p.u. Q $_{\text {load }}=3.032$ p.u.

The total initial generations and power losses are obtained as follows:

$\sum P_{G}=12.460$ p.u. $\sum Q_{G}=3.3158$ p.u.

$\mathrm{P}_{\text {loss }}=0.25848$ p.u. $\mathrm{Q}_{\text {loss }}=-1.2062$ p.u.

Table 2 shows the various system control variables i.e. generator bus voltages, shunt capacitances and transformer tap settings obtained after optimization which are within the acceptable limits. In Table 3, shows the comparison of optimum results obtained from proposed methods with other optimization techniques. These results indicate the robustness of proposed approaches for providing better optimal solution in case of IEEE-57 bus system.

Table 1: Variable Limits

\begin{tabular}{|l|l|l|l|l|l|l|l|}
\hline Reactive Power Generation Limits \\
\hline Bus no & 1 & 2 & 3 & 6 & 8 & 9 & 12 \\
\hline Qgmin & -1.4 & -.015 & -.02 & -0.04 & -1.3 & -0.03 & -0.4 \\
\hline Qgmax & 1 & 0.3 & 0.4 & 0.21 & 1 & 0.04 & 1.50 \\
\hline Voltage And Tap Setting Limits \\
\hline vgmin & Vgmax & vpqmin & Vpqmax & tkmin & tkmax \\
\hline 0.9 & 1.0 & 0.91 & 1.05 & 0.9 & 1.0 \\
\hline Shunt Capacitor Limits \\
\hline Bus no & 18 & 25 & 53 & & \\
\hline Qcmin & 0 & 0 & 0 & & \\
\cline { 1 - 2 } Qcmax & 10 & 5.2 & 6.1 & & \\
\hline
\end{tabular}


Table 2: Control variables obtained after optimization

\begin{tabular}{|l|l|}
\hline $\begin{array}{l}\text { Control } \\
\text { Variables }\end{array}$ & GC \\
\hline V1 & 1.1 \\
\hline V2 & 1.039 \\
\hline V3 & 1.031 \\
\hline V6 & 1.028 \\
\hline V8 & 1.024 \\
\hline V9 & 1.006 \\
\hline V12 & 1.018 \\
\hline Qc18 & 0.0660 \\
\hline Qc25 & 0.200 \\
\hline Qc53 & 0.0478 \\
\hline T4-18 & 1.002 \\
\hline T21-20 & 1.041 \\
\hline T24-25 & 0.860 \\
\hline T24-26 & 0.879 \\
\hline T7-29 & 1.055 \\
\hline T34-32 & 0.878 \\
\hline T11-41 & 1.011 \\
\hline T15-45 & 1.030 \\
\hline T14-46 & 0.910 \\
\hline T10-51 & 1.020 \\
\hline T13-49 & 1.060 \\
\hline T11-43 & 0.910 \\
\hline T40-56 & 0.900 \\
\hline T39-57 & 0.950 \\
\hline T9-55 & 0.950 \\
\hline
\end{tabular}

Table 3: Comparison results

\begin{tabular}{|l|l|l|l|l|}
\hline S.No. & $\begin{array}{l}\text { Optimization } \\
\text { Algorithm }\end{array}$ & Finest Solution & Poorest Solution & $\begin{array}{l}\text { Normal } \\
\text { Solution }\end{array}$ \\
\hline 1 & NLP [18] & 0.25902 & 0.30854 & 0.27858 \\
\hline 2 & CGA [18] & 0.25244 & 0.27507 & 0.26293 \\
\hline 3 & AGA [18] & 0.24564 & 0.26671 & 0.25127 \\
\hline 4 & PSO-w [18] & 0.24270 & 0.26152 & 0.24725 \\
\hline 5 & PSO-cf [18] & 0.24280 & 0.26032 & 0.24698 \\
\hline 6 & CLPSO [18] & 0.24515 & 0.24780 & 0.24673 \\
\hline 7 & SPSO-07 [18] & 0.24430 & 0.25457 & 0.24752 \\
\hline 8 & L-DE [18] & 0.27812 & 0.41909 & 0.33177 \\
\hline 9 & L-SACP-DE [18] & 0.27915 & 0.36978 & 0.31032 \\
\hline 10 & L-SaDE [18] & 0.24267 & 0.24391 & 0.24311 \\
\hline 11 & SOA [18] & 0.24265 & 0.24280 & 0.24270 \\
\hline 12 & LM [19] & 0.2484 & 0.2922 & 0.2641 \\
\hline 13 & MBEP1 [19] & 0.2474 & 0.2848 & 0.2643 \\
\hline 14 & MBEP2 [19] & 0.2482 & 0.283 & 0.2592 \\
\hline
\end{tabular}




\begin{tabular}{|l|l|l|l|l|}
\hline 15 & BES100 [19] & 0.2438 & 0.263 & 0.2541 \\
\hline 16 & BES200 [19] & 0.3417 & 0.2486 & 0.2443 \\
\hline 17 & Proposed GC & 0.22026 & 0.23018 & 0.22234 \\
\hline
\end{tabular}

Then Group Competition (GC) algorithm has been tested in standard IEEE 118-bus test system [20].The system has 54 generator buses, 64 load buses, 186 branches and 9 of them are with the tap setting transformers. The limits of voltage on generator buses are $0.95-1.1$ per-unit., and on load buses are 0.95 -1.05 per-unit. The limit of transformer rate is $0.9-1.1$, with the changes step of 0.025 . The limitations of reactive power source are listed in Table 4, with the change in step of 0.01 .

Table 4: Limitation of reactive power sources

\begin{tabular}{|l|l|l|l|l|l|l|l|}
\hline BUS & 5 & 34 & 37 & 44 & 45 & 46 & 48 \\
\hline QCMAX & 0 & 14 & 0 & 10 & 10 & 10 & 15 \\
\hline QCMIN & -40 & 0 & -25 & 0 & 0 & 0 & 0 \\
\hline BUS & 74 & 79 & 82 & 83 & 105 & 107 & 110 \\
\hline QCMAX & 12 & 20 & 20 & 10 & 20 & 6 & 6 \\
\hline QCMIN & 0 & 0 & 0 & 0 & 0 & 0 & 0 \\
\hline
\end{tabular}

The statistical comparison results of 50 trial runs have been list in Table 5 and the results clearly show the better performance of proposed Group Competition (GC) algorithm in reducing the real power loss.

Table 5: Comparison results

\begin{tabular}{|l|l|l|l|l|}
\hline Active power loss (MW) & $\begin{array}{l}\text { BBO } \\
{[\mathbf{2 1}]}\end{array}$ & $\begin{array}{l}\text { ILSBBO/ } \\
\text { strategy1 } \\
{[\mathbf{2 1}]}\end{array}$ & $\begin{array}{l}\text { ILSBBO/ } \\
\text { strategy1 } \\
{[\mathbf{2 1}]}\end{array}$ & $\begin{array}{l}\text { Proposed } \\
\text { GC }\end{array}$ \\
\hline Min & 128.77 & 126.98 & 124.78 & 118.96 \\
\hline Max & 132.64 & 137.34 & 132.39 & 122.84 \\
\hline Average & 130.21 & 130.37 & 129.22 & 119.02 \\
\hline
\end{tabular}

\section{Conclusion}

In this paper a novel approach Group Competition (GC) algorithm has been successfully solved the optimal reactive power problem, by considering various constraints. A number of individuals (solutions) as sport teams contend in a simulated group for numerous weeks. Based on the group schedule in every week, teams play in pairs and their game result is determined in terms of win or loss, given known the playing strength along with the teams' planned formations. Modeling an artificial match analysis, each team devises a new playing strategy for the subsequent week competition and this procedure is repetitive for number of seasons. In order to evaluate the validity of the proposed Group Competition (GC) algorithm, it has been tested on Standard IEEE 57,118 bus systems and simulation results reveal about the good performance of the proposed algorithm in reducing real power loss and voltage profiles are within the limits.

\section{References}

[1] O.Alsac,and B. Scott, "Optimal load flow with steady state security",IEEE Transaction. PAS 1973, pp. 745-751. 
[2] Lee K Y ,Paru Y M , Oritz J L - A united approach to optimal real and reactive power dispatch , IEEE Transactions on power Apparatus and systems 1985: PAS-104 : 1147-1153

[3] A.Monticelli , M .V.F Pereira , and S. Granville , "Security constrained optimal power flow with post contingency corrective rescheduling", IEEE Transactions on Power Systems :PWRS-2, No. 1, pp.175-182.,1987.

[4] Deeb N ,Shahidehpur S.M ,Linear reactive power optimization in a large power network using the decomposition approach. IEEE Transactions on power system 1990: 5(2) : 428-435

[5] E. Hobson ,'Network consrained reactive power control using linear programming, ' IEEE Transactions on power systems PAS -99 (4) ,pp 868=877, 1980

[6] K.Y Lee ,Y.M Park , and J.L Oritz, "Fuel -cost optimization for both real and reactive power dispatches", IEE Proc; 131C,(3), pp.85-93.

[7] M.K. Mangoli, and K.Y. Lee, "Optimal real and reactive power control using linear programming”, Electr.Power Syst.Res, Vol.26, pp.1-10,1993.

[8] K.Anburaja, "Optimal power flow using refined genetic algorithm”, Electr.Power Compon.Syst , Vol. 30, 1055-1063,2002.

[9] D. Devaraj, and B. Yeganarayana, "Genetic algorithm based optimal power flow for security enhancement”, IEE proc-Generation.Transmission and. Distribution; 152, 6 November 2005.

[10] Husseinzadeh Kashan, "League Championship Algorithm: A new algorithm for numerical function optimization," in Proceedings of the International Conference of Soft Computing and Pattern Recognition (SoCPaR 2009), IEEE Computer Society, pp. 43-48, 2009.

[11] http://en.wikipedia.org/wiki/ Sports_league.

[12] http://www.talkfootball.co.uk/guides/football_formations.html.

[13] E. Bruke, D. de Werra, and J Kingstone, "Colorings and related topics; Applications to timetabling," in Handbook of Graph Theory, J. L. Gross, and J. Yellen, Ed. CRC PRESS, 2004.

[14] Husseinzadeh Kashan, B. Karimi, and F. Jolai, "Effective hybrid genetic algorithm for minimizing makespan on a single-batchprocessing machine with non-identical job sizes," Int $\mathrm{J}$ Prod Res, vol. 44, pp. 2337-2360, 2006.

[15] K. Deb, "An efficient constraint handling method for genetic algorithms," Comput Method Appl M, vol. 186, pp. 311-338, 2000.

[16] R. Monroy, G.Arroyo-Figueroa, L. E. Sucar, and H. Sossa, Eds. Heidelberg, Germany: Springer Verlag, lecture Notes in Artificial Intelligence No. 2972, pp. 707-716, 2004.

[17] E. Mezura-Montes, J. Vel'azquez-Reyes, and C. A. C. Coello, "Promising Infeasibility and Multiple Offspring Incorporated to Differential Evolution for Constrained Optimization," in Proceedings of the Genetic and Evolutionary Computation Conference (GECCO'2005), pp. 225232, 2005.

[18] Chaohua Dai, Weirong Chen, Yunfang Zhu, and Xuexia Zhang, "Seeker optimization algorithm for optimal reactive power dispatch,” IEEE Trans. Power Systems, Vol. 24, No. 3, August 2009, pp. 1218-1231.

[19] J. R. Gomes and 0. R. Saavedra, "Optimal reactive power dispatch using evolutionary computation: Extended algorithms," IEE Proc.-Gener. Transm. Distrib.. Vol. 146, No. 6. Nov. 1999.

[20] IEEE, "The IEEE 30-bus test system and the IEEE 118-test system", (1993), http://www.ee.washington.edu/trsearch/pstca/.

[21] Jiangtao Cao, Fuli Wang and Ping Li, "An Improved Biogeography-based Optimization Algorithm for Optimal Reactive Power Flow" International Journal of Control and Automation Vol.7, No.3 (2014), pp.161-176.

*Corresponding author.

E-mail address: gklenin@ gmail.com 